\title{
Submucosal tunneling endoscopic septum division of a Zenker's diverticulum
}

\author{
Konstantinos Delis ${ }^{a}$, John Robotis ${ }^{a}$, Epistimi Sachitzi ${ }^{b}$, Ekaterini Mastronikolac
}

Metropolitan Hospital, Neo Faliro, Piraeus, Greece

New incision techniques and devices render flexible endoscopic treatment of Zenker's diverticulum (ZD) effective and safe. Techniques described so far include the use of a specific diverticuloscope or a cap and different types of knives and scissors to perform direct dissection of the $\mathrm{ZD}$ septum, which consists of mucosa and cricopharyngeal muscle (CM) fibers [1]. Herein, we present a novel technique called submucosal tunneling endoscopic septum division (STESD), described recently by Li et al [2], based on peroral endoscopic myotomy technique that achieves $\mathrm{CM}$ dissection while respecting mucosal integrity (Fig. 1). To date, only few cases have been described in the literature, underlining the need for further evaluation $[1,3]$.

A 73-year-old female underwent STESD in our endoscopy unit for the treatment of a 35-mm ZD, under general anesthesia and $\mathrm{CO}_{2}$ insufflation. An ERBE generator (Germany), a transparent cap mounted on the tip of the endoscope, and Olympus TT, Dual ITnano knives (Germany), alternatively, were used. After submucosal injection of methylene blue solution, a small longitudinal mucosal incision was made $2.5 \mathrm{~cm}$ proximal to the ZD septum. Through this, a submucosal tunnel was created up to the septum, exposing CM on both sides. Myotomy followed towards the bottom of the ZD. After hemostasis of all bleeding vessels with coagulation grasper, four clips closed the initial incision. The patient was discharged the next day with no complications.

Potential advantages of STESD over flexible endotherapy are the lower risk of perforation and secondary infections, due to the preserved mucosal integrity, but also the ability for deeper myotomy and thus reduced recurrence rates [1].

Departments of a Gastroenterology (Konstantinos Delis, John Robotis), ${ }^{\mathrm{b}}$ Anesthesiology (Epistimi Sachitzi), and 'Internal Medicine (Ekaterini Mastronikola), Metropolitan Hospital, Neo Faliro, Piraeus, Greece

\section{Conflict of Interest: None}

Correspondence to: Konstantinos C. Delis, MD, PhD, Director, Dept. of Gastroenterology, Metropolitan Hospital, 9 Ethnarchou Makariou \& 1 E. Venizelou Streets, 18547 Neo Faliro, Piraeus, Greece, e-mail: delkc1@gmail.com

Received 17 June 2018; accepted 1 July 2018; published online 20 July 2018

DOI: https://doi.org/10.20524/aog.2018.0296
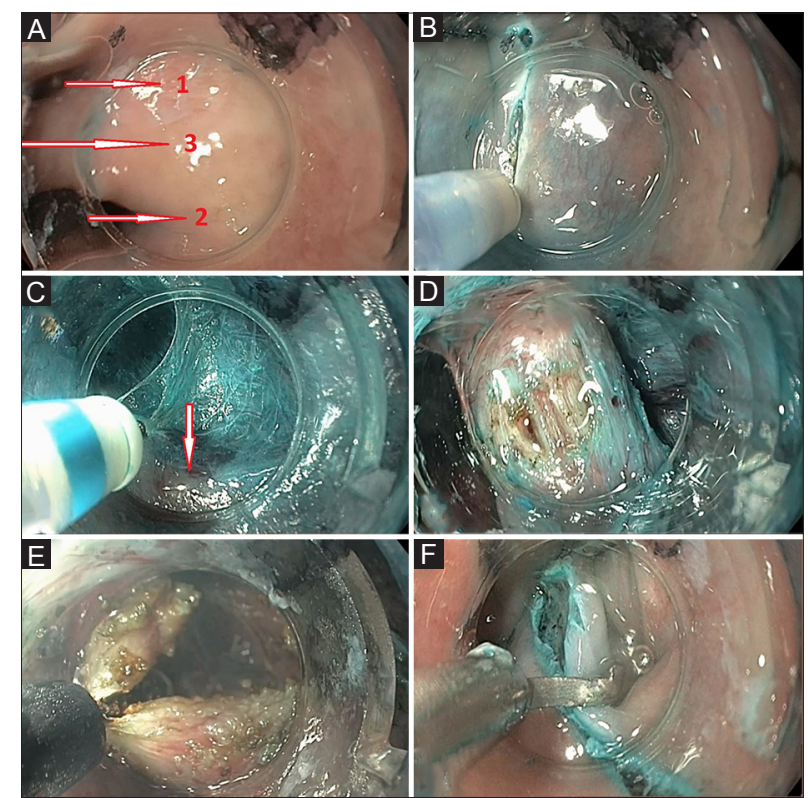

Figure 1 Submucosal tunneling endoscopic septum division procedure. (A) Endoscopic view of the esophagus (arrow 1), Zenker's diverticulum (ZD) (arrow 2) and ZD septum (arrow 3). (B) Creation of a longitudinal incision $2.5 \mathrm{~cm}$ above the septum on a bleb formed after submucosal injection of $4 \mathrm{~mL}$ methylene blue/ $\mathrm{NaCl} 0.9 \%$ solution. (C) Submucosal tunneling on the esophageal side of the septum delineating $\mathrm{CM}$ (arrow). The cap mounted on the tip of the endoscope significantly improves the operating space. (D) Exposed CM. (E) Myotomy. (F) Clips for closing the incision

\section{References}

1. Ishaq S, Sultan H, Siau K, Kuwai T, Mulder CJ, Neumann H. New and emerging techniques for endoscopic treatment of Zenker's diverticulum: state-of-the-art review. Dig Endosc 2018;30:449-460.

2. Li QL, Chen WF, Zhang XC, et al. Submucosal tunneling endoscopic septum division: a novel technique for treating Zenker's diverticulum. Gastroenterology 2016;151:1071-1074.

3. Hernández Mondragón OV, Solórzano Pineda MO, Blancas Valencia JM. Zenker's diverticulum: submucosal tunneling endoscopic septum division (Z-POEM). Dig Endosc 2018;30:124. 